\title{
Induction of Abscess by Non-abscess Producer Staphylococci Using Staphylococcal Fatty Acid Modifying Enzyme (FAME)
}

\author{
Raga I. O. ${ }^{1, *}$, Gameel A. A. ${ }^{2}$, El-Sanousi S. M. ${ }^{3}$ \\ ${ }^{1}$ Department of Microbiology, Faculty of Veterinary Science, University of Nyala, P. O. Box 155, Nyala Sudan \\ ${ }^{2}$ Department of Pathology, Faculty of Veterinary Medicine, University of Khartoum, P. O. Box 32, Khartoum Sudan \\ ${ }^{3}$ Department of Microbiology, Faculty of Veterinary Medicine, University of Khartoum, P. O. Box 32, Khartoum Sudan \\ *Corresponding author: ragaibrahimomar@gmail.com
}

\begin{abstract}
Stahpylococcus epidermidis (S. epidermidis), S. warneri and S. aureus subsp. anaerobious were isolated from sheep abscess. Crude FAME was extracted from supernatant fluid of a 24hrs culture of S. aureus subsp. anaerobious grown in Trypticase Soy Broth at $37^{\circ} \mathrm{C}$ with continuous agitation. Fourteen heads of sheep were used. Three of them were inoculated with S. epidermidis + FAME and other three were inoculated with $S$. warneri + FAME. Eight animals were divided into four groups, two animals in each, used as control and inoculated with $S$. epidermidis, S. warneri, S. aureus subsp. anaerobious and FAME. All animals were inoculated subcutaneously at the neck region. After fourteen to eighteen days, sites inoculated with $S$. epidermidis + FAME, $S$. warneri + FAME and $S$. aureus subsp. anaerobious showed abscesses grossly then confirmed bateriologically and histopathologically, while those inoculated with $S$. epidermidis alone, $S$. warneri alone and FAME showed no abscess.
\end{abstract}

Keywords: Stahpylococcus, abscess, fatty acid modifying enzyme

Cite This Article: Raga I. O., Gameel A. A., and El-Sanousi S. M., "Induction of Abscess by Non-abscess Producer Staphylococci Using Staphylococcal Fatty Acid Modifying Enzyme (FAME)." American Journal of Microbiological Research, vol. 6, no. 1 (2018): 33-37. doi: 10.12691/ajmr-6-1-5.

\section{Introduction}

Abscess disease in sheep has a great economical importance in Sudan. It is caused by S. aureus subsp. anaerobious and characterized by superficial lymph nodes enlargement. For the organism to survive and multiply in the host tissue and causes abscess it must produce an estrifying enzyme known FAME which inactivates the bacteriocidal fatty acids $[4,5,7]$. In natural abscess disease, many Stahpylococcus spp. have been isolated. Some of them were known to produce FAME but unable to form abscess; from these S. epidermidis and S. warneri (coagulase-negative Staphylococci) are examples [6]. FAME activity was detected in $54 \%$ of CNS and $80 \% S$. aureus strains surveyed but none in E. coli or S. uberis. While some CNS strains produced FAME activity comparable to the lab strain of $S$. aureus, the pattern of FAME activity varied among strains and across species of staphylococci [9].

S. aureus FAME has a pH optimum between 5.5-6.0 and a temperature optimum of about $40^{\circ} \mathrm{C}$. Expression of FAME is controlled genetically by the golbal regulators Agr and Sar [2]. FAME has an extracellular activator which can increase FAME expression and activity when added to the FAME-producer Stahpylococcus culture [3].

\section{Materials and Methods}

\subsection{Preparation of Organisms}

Abscesses were collected from sheep for isolation of $S$. epidermidis, S.warneri and S. aureus subsp. anaerobious. The isolates were identified according to $[1,8]$. S. aureus subsp. anaerobius was grown microaerophilically in ten $\mathrm{ml}$ nutrient broth at $37^{\circ} \mathrm{C}$ overnight while, S. epidermidis and $S$. warneri were grown aerobically in $10 \mathrm{ml}$ nutrient broth at $37^{\circ} \mathrm{C}$ overnight. Serial ten-fold dilution from $1 \mathrm{ml}$ of each culture was made and inocula from dilutions $10^{-1}$ (containing about $10^{4}$ bacterial cells) and $10^{-3}$ (containing about $10^{3}$ bacterial cells) were used.

\subsection{Preparation of Crude FAME}

Crude FAME was prepared according to the method of Long [6]. S. aureus subsp. anaerobius was grown microaerophilically in $100 \mathrm{ml}$ of Trypticase Soy Broth (TSB) at $37^{\circ} \mathrm{C}$ for $18 \mathrm{hrs}$. with continuous shaking. The culture was centrifuged at 3000 r.p.m. for 30 minutes using cold centrifuge and the supernatant fluid was sterilized by filtration using $0.22 \mu \mathrm{m}$. filter membrane. The culture filtrate was concentrated to half volume at $4{ }^{\circ} \mathrm{C}$ using dialysis tubes and carbowax. 


\subsection{Inoculation of Experimental Animals (Sheep)}

Fourteen healthy fattened sheep were clipped and divided into groups then labeled as follows:

Group (1): Three animals were inoculated with $0.5 \mathrm{ml}$ of dilution $10^{-1}$ of $S$. epidermidis $+0.5 \mathrm{ml}$ of FAME and $0.5 \mathrm{ml}$ of dilution $10^{-1}$ of $S$. epidermidis $+1.0 \mathrm{ml}$ of FAME at each site of the neck region.

Group (2): Three animals were inoculated with $0.5 \mathrm{ml}$ of dilution $10^{-1}$ of $S$. warneri $+0.5 \mathrm{ml}$ of FAME and $0.5 \mathrm{ml}$ of dilution $10^{-1}$ of $S$. warneri $+1.0 \mathrm{ml}$ of FAME at each site of the neck region.

Group (3): Eight animals were divided into four equal subgroups (3a-3d) which were inoculated with: $0.5 \mathrm{ml}$ of dilution $10^{-1}$ of $S$. epidermidis, $0.5 \mathrm{ml}$ of dilution $10^{-1}$ of S. warneri, $0.5 \mathrm{ml}$ of FAME and $0.5 \mathrm{ml}$ of dilution $10^{-3}$ of $S$. aureus subsp. anaerobious, respectively and kept as control.
All animals were inoculated $\mathrm{S} / \mathrm{C}$ at the neck region, followed up daily and any clinical observations were recorded. After fourteen to eighteen days they were slaughtered and samples were collected for bacteriological examination. Sections from lesions were fixed in $10 \%$ neutral formalin for histopathological examination.

\section{Results}

Inoculation of sheep with treated bacteria resulted in abscess formation (Figure 1 and Figure 2). Transient increase in body temperature and mild tissue reaction at the inoculation sites were observed in the first three days of inoculation. At day six some swellings developed into abscesses which ruptured by day eight (Figure 3 and Figure 4). Other swellings remained closed until incised at postmortem. The control sites which were injected with $S$. epidermidis, $S$. warneri and FAME revealed in no swelling or caseation (Table 1).

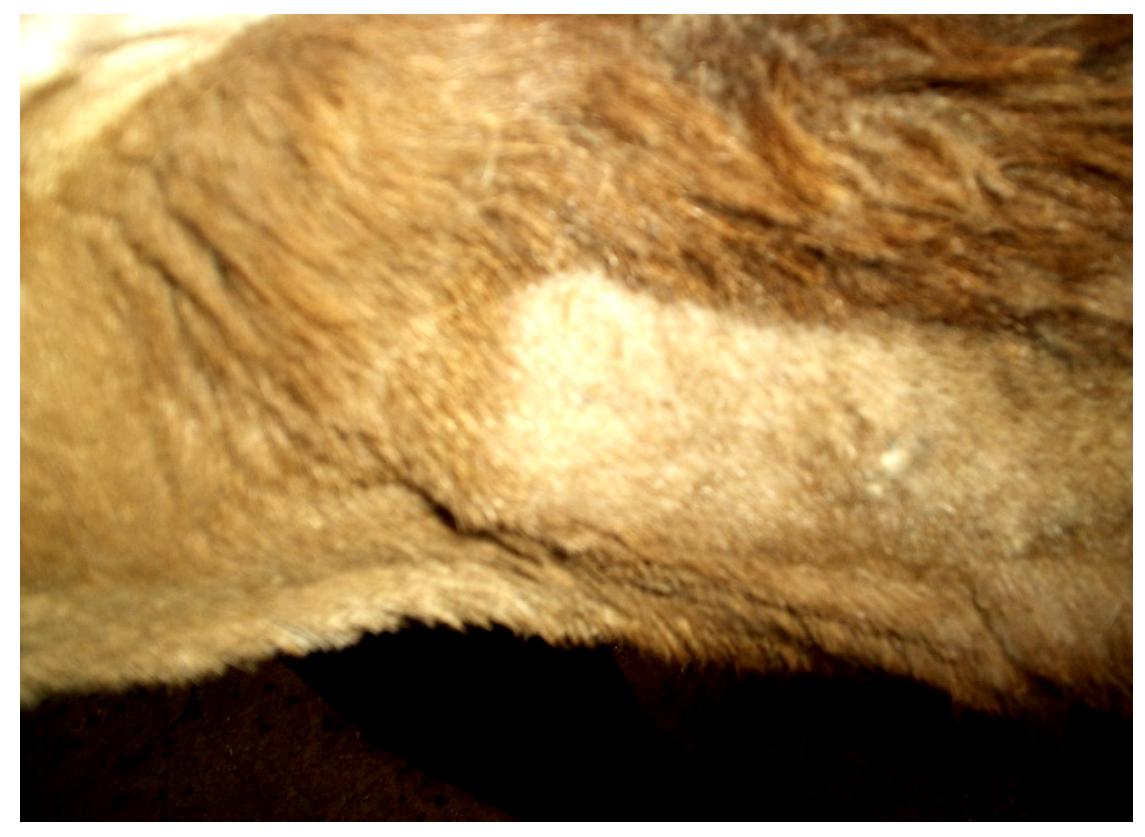

Figure 1. Subcutaneous abscess in sheep experimentally infected with $S$. epidermidis plus FAME

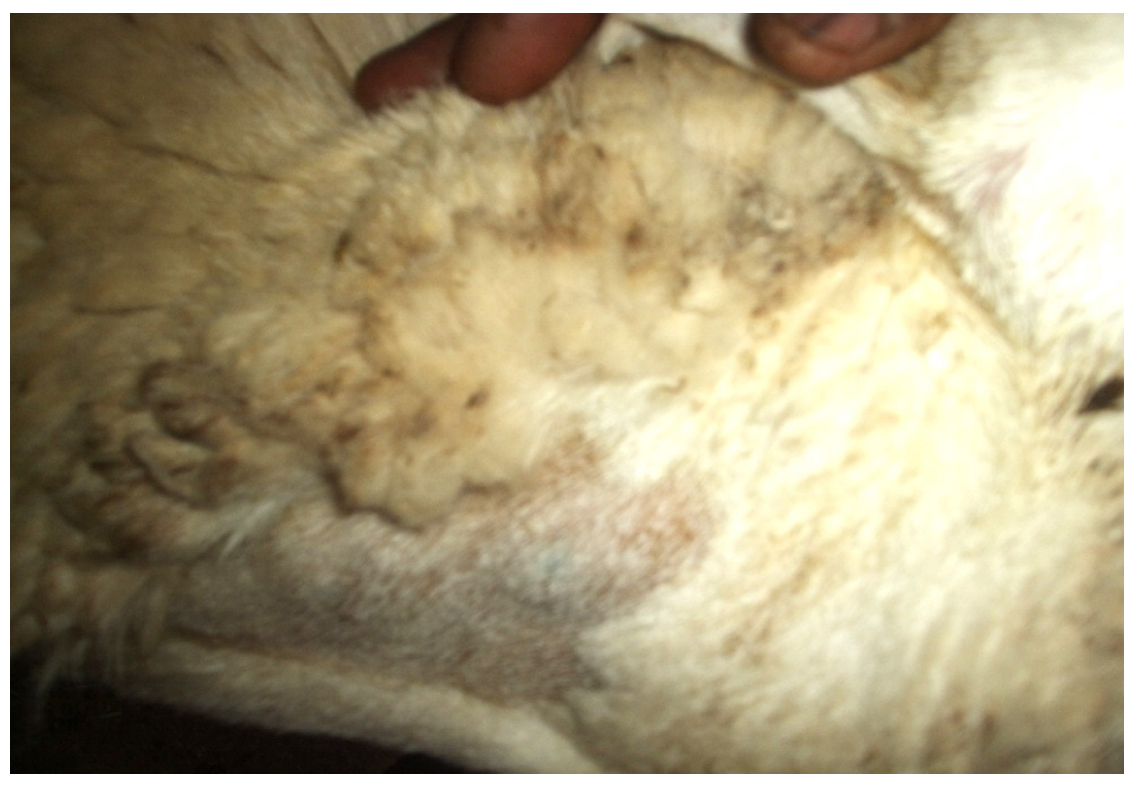

Figure 2. Subcutaneous abscess in sheep experimentally infected with $S$. warneri plus FAME 
Table 1. show the comparison of abscess sizes (cm.) obtained from addition of FAME to $S$. epidertmidis and $S$. warneri with their control positives

\begin{tabular}{|c|c|c|c|c|}
\hline $\begin{array}{c}\text { Animal No. group } \\
(1 \text { and } 2)\end{array}$ & $\begin{array}{c}0.5 \mathrm{ml} \text { of FAME }+0.5 \mathrm{ml} \\
\text { of S. epidermidis }\end{array}$ & $\begin{array}{c}\text { 0.5ml of FAME }+0.5 \mathrm{ml} \text { of } \\
\text { S. warneri }\end{array}$ & $\begin{array}{c}0.5 \mathrm{ml} \text { of S. epidermidis } \\
\text { Alone }\end{array}$ & \begin{tabular}{c}
$0.5 \mathrm{ml}$ of S. warneri Alone \\
\hline 1
\end{tabular} \\
\hline 2,1 & 0.6 & $\geq 0.1$ & $\geq 0.1$ \\
\hline 2 & 1.2 & 1.0 & $\geq 0.1$ & $\geq 0.1$ \\
\hline 3 & 1.2 & 0.8 & - & - \\
\hline
\end{tabular}

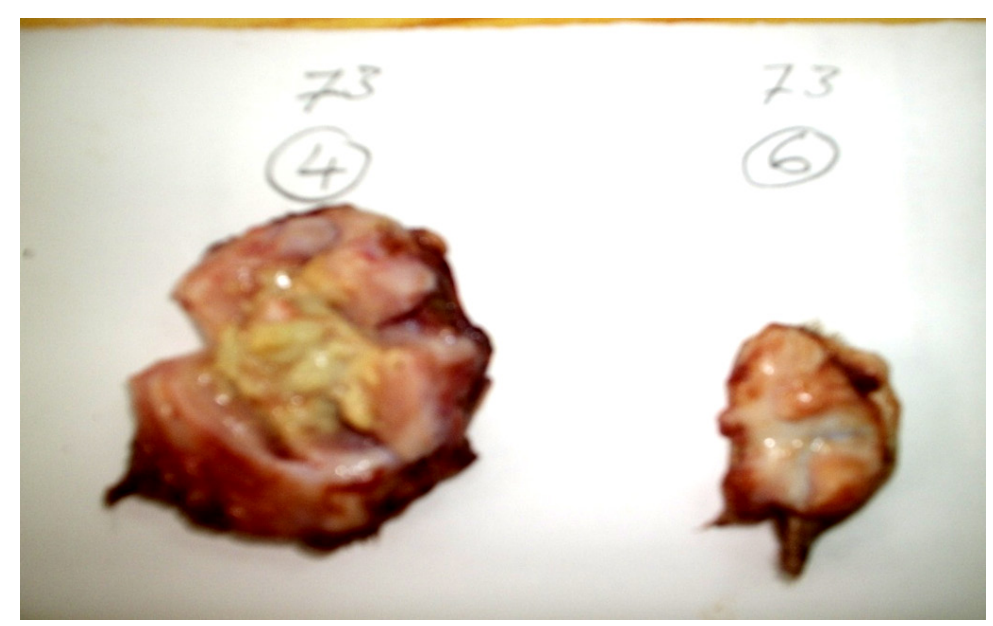

Figure 3. Skin: Image $(73,4)$ shows abscess formation at the site of $S$. epidermidis plus FAME injection And image $(73,5)$ shows Injection site of S. epidermidis alone

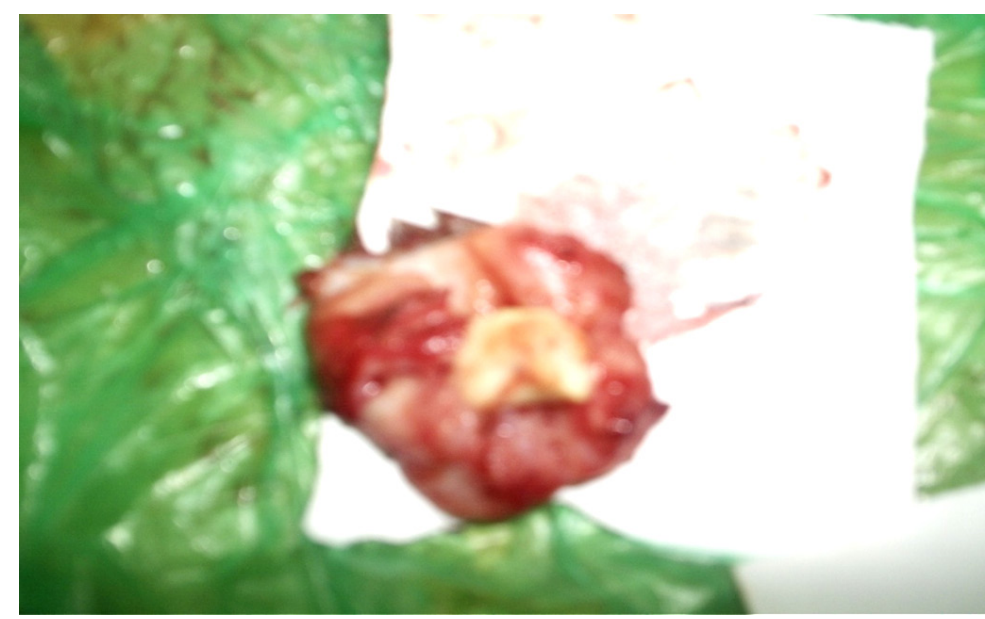

Figure 4. Abscess formation at the injection site of $S$. warneri plus FAME

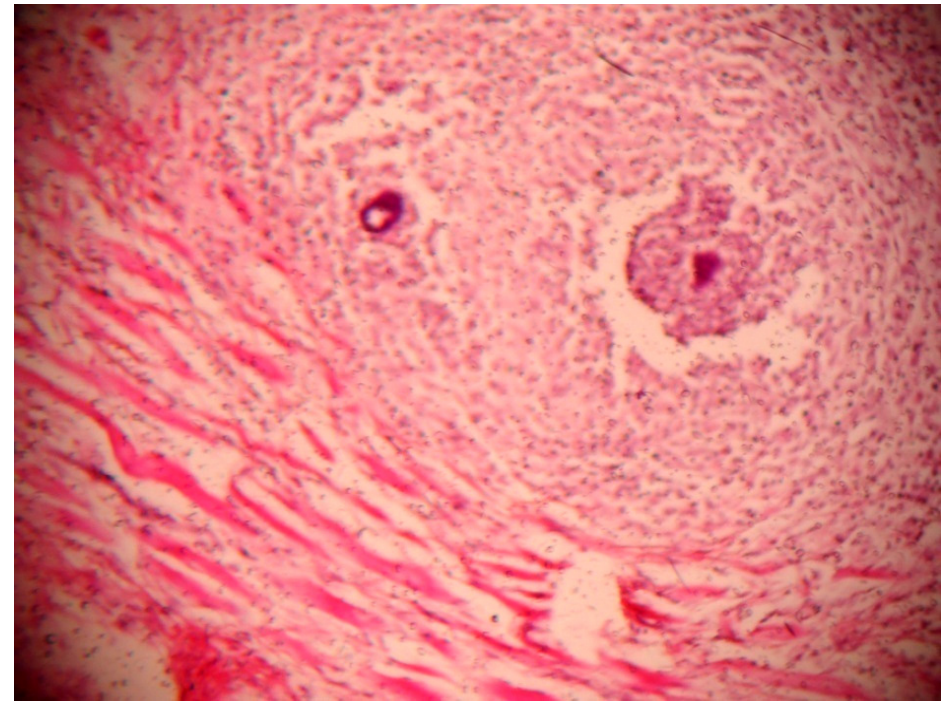

Figure 5. Skin: Subcutaneous tissue showing a pyogranuloma (H and E x 100) (section from site injected with S. epidermidis plus FAME) 


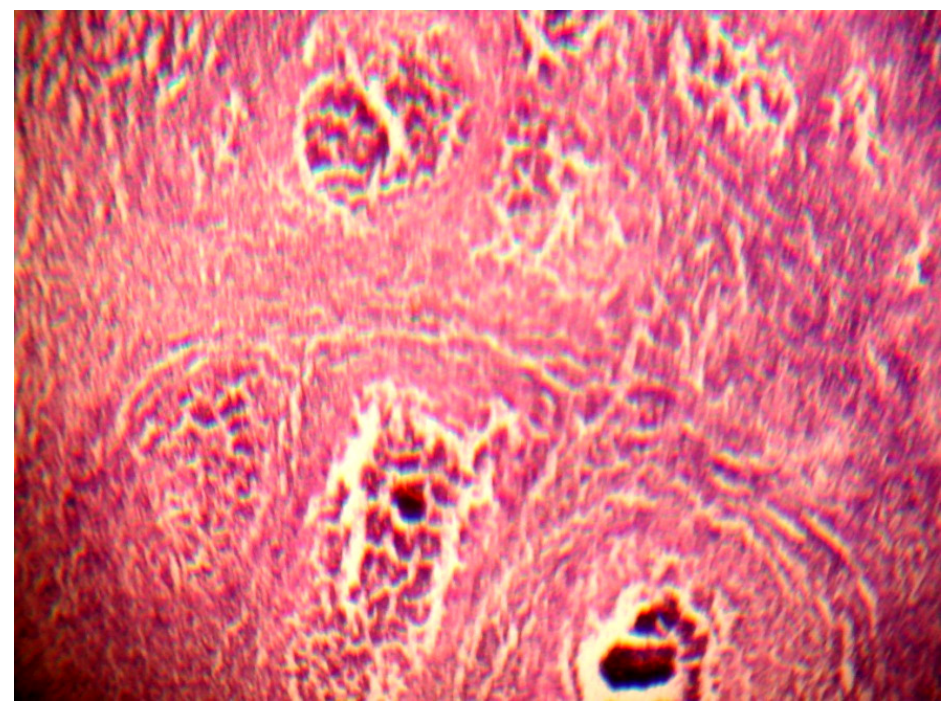

Figure 6. Skin: Subcutaneous tissue showing multiple abscess formation (H and E x 100). (Section from site injected with S. warneri plus FAME)

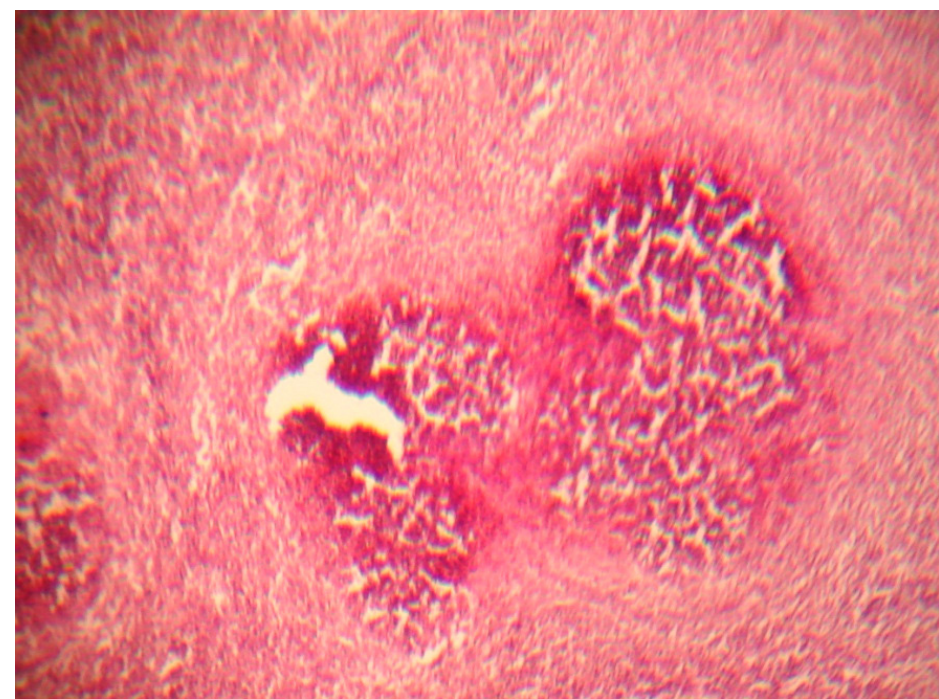

Figure 7. Section showing dermal abscesses ( $\mathrm{H}$ and $\mathrm{E} x \mathrm{100})$. (section from site injected with S. epidermidis plus FAME)

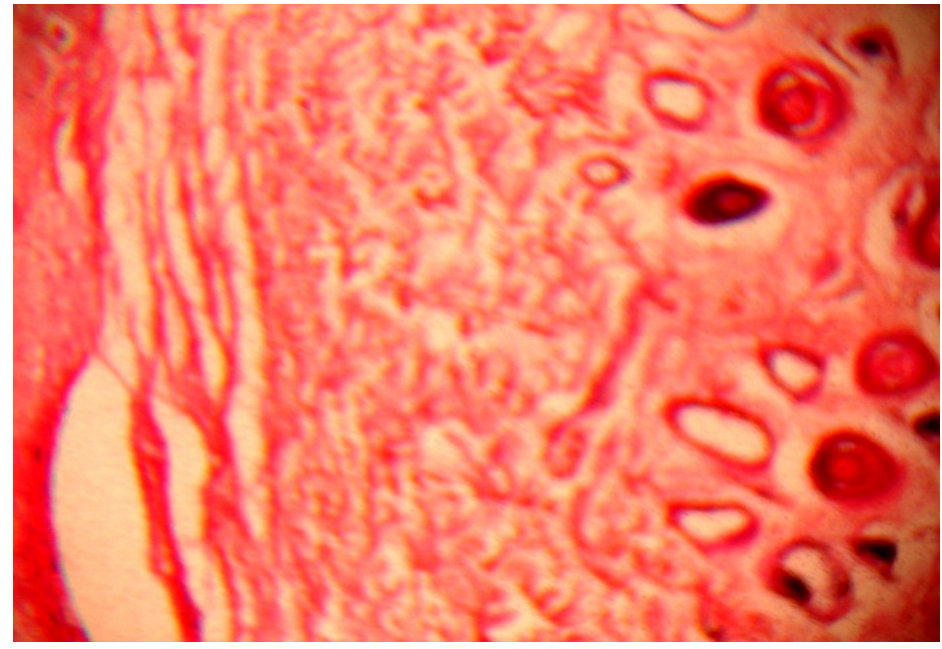

Figure 8. Skin section showing slight dermal edema (H and E x 100) ( section from site injected with FAME alone)

Results were confirmed histopathologically by the presence of abscess in sites inoculated with $S$. epidermidis plus FAME and $S$. warneri plus FAME. A chronic pyogranulomatous reaction was seen; composed of dense collection of mononuclear, lymphocytes and plasma cells with neutrophils in the centre. Most sections showed dermal edema, fibrosis, mononuclear infiltration (observed also perivascularly), subcutaneous muscle degeneration and necrosis with widened and fibrosed intermuscular connective tissues. Pyogranulomas and 
wide suppuration were seen in deep dermis and subcutaneous tissues. In some sections the granulomatous reaction was not severe and other one showed dermal haemorrahge (Figure 5, Figure 6 and Figure 7). FAME injected sites showed no significant gross change and hitopathologically there was dermal edema. Subcutaneous muscles stained pale and some muscle fibers showed intense eosinophilia (Figure 8).

\section{Discussion}

Previous studies about abscess formation showed that, organism to form abscess and causes the disease must possesses two enzymes: FAME and lipase. Those studies explained the role of FAME in abscess formation in vitro.

Studies in Sudan were conducted on different aspects of the disease but there is no work being published on bacterial enzymes specially FAME; the main factor of abscess formation.

As shown in this study, abscess could be generated in animals (sheep) experimentally by non-abscess producer Staphylococci when FAME was added. These results confirmed the findings reported by [4,5,7], who assured that, FAME is an important factor in the process of abscess formation. Other work conducted on extracellular activator of FAME explained that addition of $S$. aureus activator to $S$. epidermidis cultures increased FAME production but there was no increase or inhibition in FAME production when $S$. epidermidis activator was added to $S$. aureus cultures [3]. Also other report showed that, some CNS strains produced FAME activity comparable to the lab strain of $S$. aureus, while the pattern of FAME activity varied among strains and across species of staphylococci [9]. In Sudan also found that injection of S. epidermidis alone (isolated from Sheep abscess) could not produce abscess but when inoculated with other bacteria ( $S$. aureus subsp. anaerobious) abscess was produced (Unpublished data). Three later observations emphasized the present result.

The results of the present study suggest that, $S$. epidermidis FAME is non-functional and abscess formed due to $S$. aureus subsp. anaerobious FAME or it was activated by S. aureus activator.

\section{Conclusion and Recommendation}

We concluded that FAME is an important factor in abscess formation, and non-abscess producer Staphylococcal FAME can be activated, so as to get rid of the disease must inactivate the FAME. Further researches must be conducted for more information.

\section{Competing Interests}

The authors declare that they have no competing interests.

\section{References}

[1] Barrow, G. I. and Feltham R. K. A. (2003). Cown and Steel's Manual for the Identification of Medical Bacteria. $3^{\text {rd }}$ edition. Cambridge University.

[2] Chamberlain, N. R. and Imanoel, B. (1996) Genetic regulation of fatty acid modifying enzyme from Staphylococcus aureus. J. of Med. Microbiol., 44 (2):125-129. Press.

[3] Chamberlain, N. R. (1999). Identification and partial characterization of an extracellular activator of fatty acid modifying enzyme (FAME) expression in Staphylococcus epidermidis. J. of Med. Microbiol., 48: 245-252.

[4] Dye, E.S.and Kapral, F.A. (1981). Survival of Staphylococcus aureus in intraperitoneal abscess. J. Med. Microbiol., 14: 185-194.

[5] Kapral, F. A.; Smith, S. and Lal, D. (1992). The esterification of fatty acids by Staphylococcus aureus fatty acid modifying enzyme (FAME) and its inhibition by glycerides. J. of Med. Microbiol., 37: 235-237.

[6] Long, J. P.; Hart, J.; Albers, W. and Kapral, F. A. (1992). The production of fatty acid modifying enzyme (FAME) and lipase by various Staphylococcal species. J. of Med. Microbiol., 37: 232-234.

[7] Mortensen, J. E.; Shryock, T. R. and Kapral, F. A. (1992). Modification of bactericidal fatty acids by an enzyme of Staphylococcus aureus. J. of Med. Microbiol., 36:293-298.

[8] Saeed, K. B. and El-Sanousi, S. M. (1995). Scheme for identification of Staph. Species protocol, Department of Microbiology, Fac. of Vet. Science, Univ. of Khrtoum. (Personal communication).

[9] Thea Lu, Joo Youn Park, Kelleen Parnell, Larry K Fox, and Mark A McGuire (2012). Characterization of fatty acid modifying enzyme activity in staphylococcal mastitis isolates and other bacteria. J. of BMC Res Notes, 5: 323. 